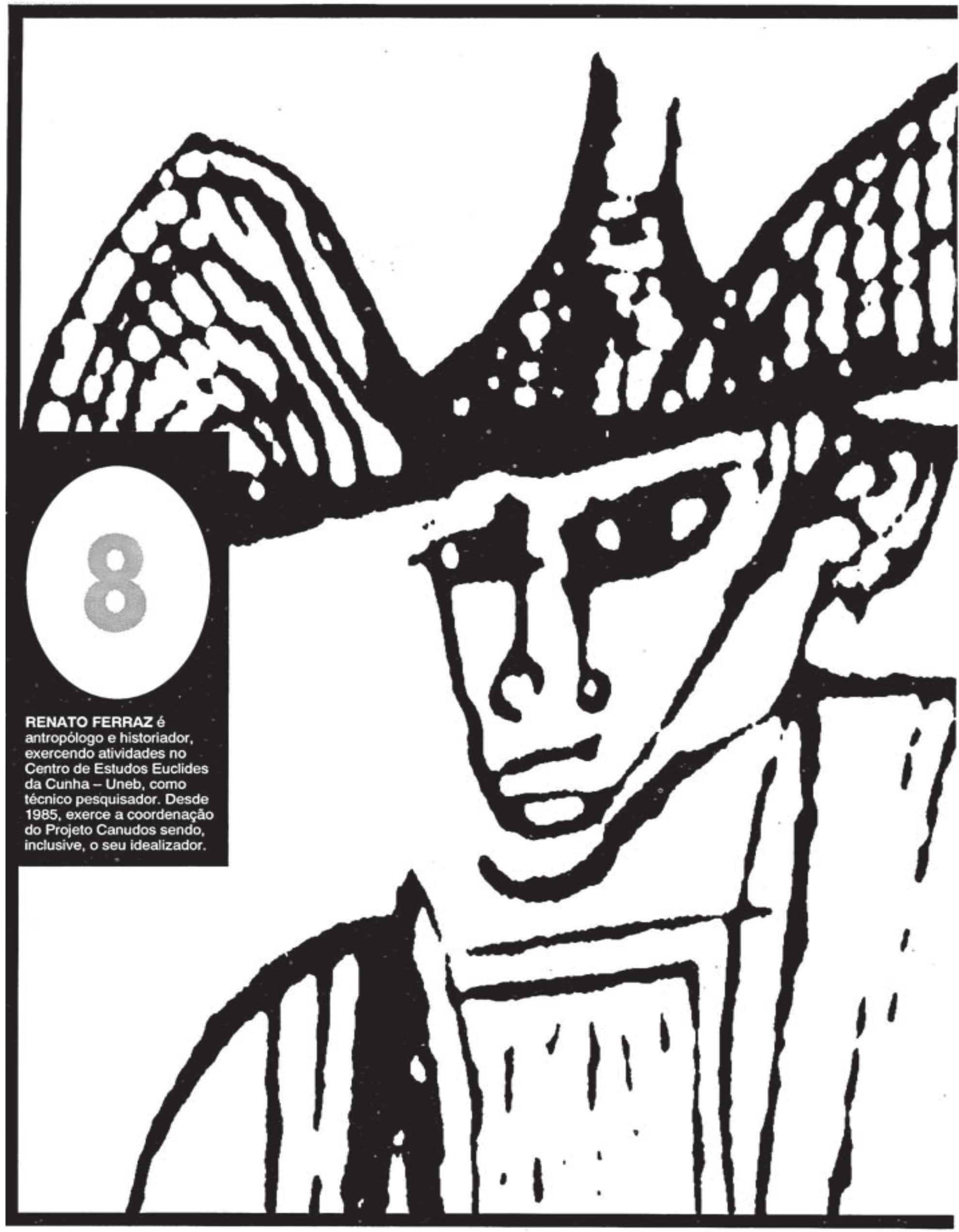




\section{- centenário do Belo Monte e algumas reflexões sobre ficção e história}

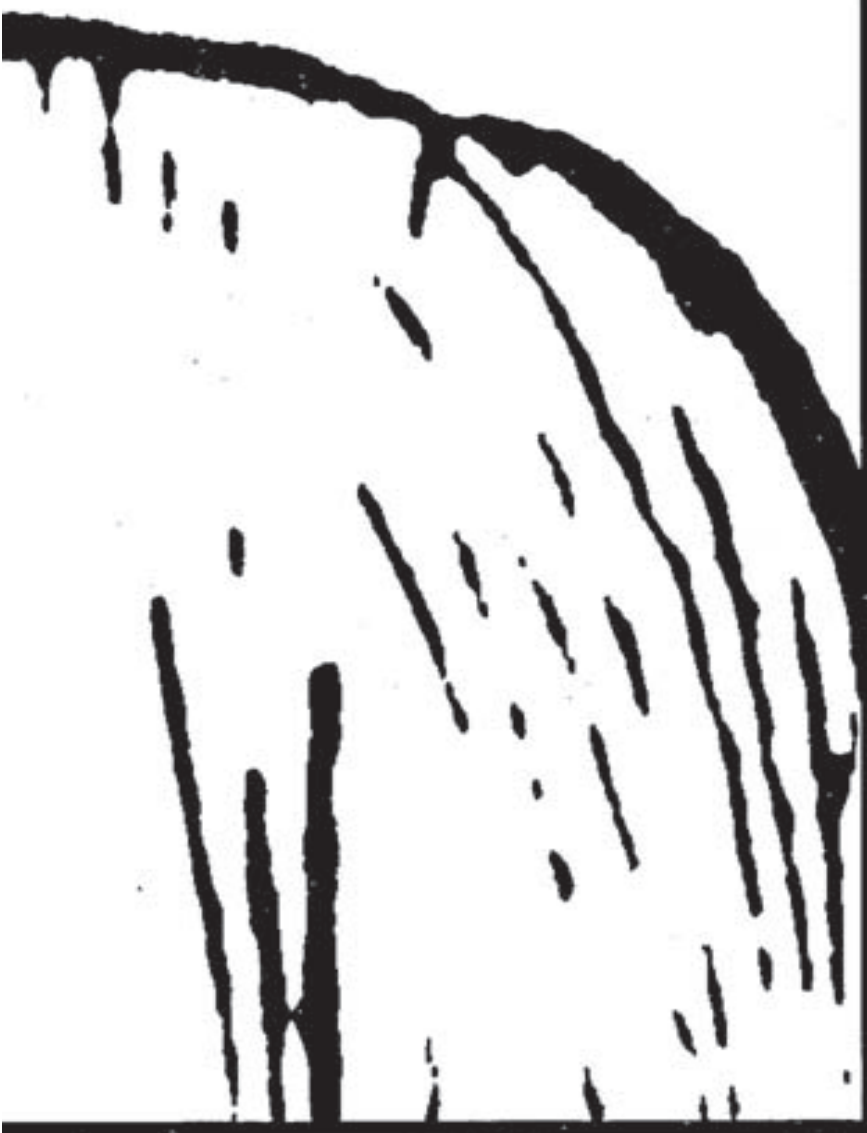

Durante a segunda semana de junho do corrente ano (1) a Universidade do Estado da Bahia (Uneb), liderando um conglomerado de outras instituições, promoveu na atual cidade de Canudos uma extensa programação que visava assinalar o transcurso do primeiro centenário de fundação do extinto arraial do Belo Monte pelo grande condutor do povo sertanejo Antônio Conselheiro.

Inserida, com certa desvantagem, no âmbito dasfestividades religiosase profanas dedicadas a Santo Antonio, padroeiro da comunidade, a III Semana Cultural de Canudos terminou por constituir-se, segundo o dizer de muitos, na mais importante reunião de "canudistas" realizada nos últimos anos no país. Na realidade, o êxito incontestável das palestras, conferências e mesas-redondas deveu-se não somente às notórias qualificaçōes dos especialistas convidados (2), como à sua subordinação aos dois grandes temas previamente propostos: quem 
1 Mals precisamente entre os dias $7 \cdot 12$.

2 Estiverampresentescomocon. ferencistae o profeseor Jost Calasans, o padre Alexandre Otten SVD, a professore Luitgarde Cavalcanti Barrose - professor Ferdinand $C$ os outros espocialistas la estiveram. participando dos debates. como oprolessor Fadel David, - protessor Goraldo Tayior, Adelino Brandilo. Foram, sobramaneira Iamentadas as rupla por motvo de Isaura Pereira do Queiroz, Josildete Consorte o do professor Nelson Werneck Sodre.

3 Vale registrar que no dia 12 de junho a CAmara de Vereado. junho a Camara de VereadoJosé Calasans o primeiro th. tuse Calasans o primeiro ti. tulo de cidadania concedido pelo municipio, traduzindo o reconhecimento do powo de Canudos ao mais notivel es. tudioso do seu passado.

4 A expressaso "Canudos fol o nosso ítimo quilombo" 6 da astoria do prolesscr e tern sido alvo de algumas das suas pro. ocupaçee nos últimos tem. pos.

5 A publicacalo inthula-se intos Brésile o número em questáo 60 correspondente acs meses julho-agosto/93.

6 Com raras excecobes, os nossos patricios optaram pelos assuntos mais superficiais. talvez os únicos que ithes fol possivel vislumbar. Um deles proteriu concentrar-senos as: pectos ditos de copalcozinha. tais como o número de cestas básicas que seria possivel ad. quirir com as somas protertura, ou uma "importan. $0^{*}$ investigaçáo sobre a auto. ra do pedido feito ao Exircito para a montagem de um acantonamento que abrigou cerca de trezentos alunos e protessores de colégios. universidades, alóm de artis. tas de teatro, músicos, otc. foi Antônio Conselheiro e o que era o Belo Monte ou Canudos?

Por quatro dias, em auditório improvisado no clube Vaza-Barris, uma platéia de estudantes, professores e interessados teve a oportunidade de, durante horas seguidas, discutir detalhadamente aspectos da vida e da personalidade do beato cearense, da sua cidadela indomável e das multidōes que o seguiram até a morte.

Todavia, a variedade de assuntos abordados năo foi capaz de mascarar algumas preocupaçōes compartilhadas por muitos dos presentes e que, como seria de esperar, terminaram por polarizar boa parte das discussōes mais calorosas, especialmente as que se seguiram ao sem-número de perguntas suscitadas pela conferência mais ansiosamente esperada que foi a proferida pelo professor José Calasans (3).

$\mathrm{Na}$ sua fala, o professor Calasans, além de oferecer ao conhecimento dos estudiosos os resultados das suas mais recentes pesquisas sobre o episódio de Masseté, discorreu minuciosamente, com a segurança que lhe permitem os seus quarenta anos de estudos da história de Canudos e o incontestadotítulode maior conhecedor das suas fontes originais, sobre algumas facetas até aquidesprezadas pelos historiadores, tais como a participação dos negros (4), dos indios kiriris de Mirandela e dos caimbés de Massacará, o muito pouco conhecido cotidiano do arraial conselheirista e a organizaçãodoestadoteocráticoestabelecidoàsmargens do Vaza-Barris em junho de 1893.

Entretanto, foi um jornalista francês, $P$. Postal, quem, no artigo intitulado "Canudos Revisité", publicado em uma pequena revista de informação sobre o Brasil (5), ao contrário dos vários jornalistas brasileiros presentes, atingiu o ponto nevrálgico que estava subjacente em todas as discussōes, constituindo-se, portanto, em um "nó" a desatar (6).

Em seu sucinto relato, que avisa, desde o subtítulo, que as comemoraçōes do centenáriodeCanudos “... restent partagéesentre la verité historique et le mythe", Postal coloca o professor Calasans como o mais representativo membro de uma escola de historiadores que apenas se esforça por acumular fatos que têm permitido "afinar" a imagem da sociedade conselheirista e da guerra. Aqui, năo parece inteiramente correta a assertiva, sobretudo porque não se tem conhecimento de nenhuma escola de historiadores que tenha como chefe ou prin- cipal representante o maior estudioso do tema.

Na verdade, o professor Calasans é geralmente consultadoe ouvidoem decorrência do seu imenso conhecimento e da sua permanente disposição para repassá-lo(7). De resto, sua postura como historiador em nada difere da de Capistrano de Abreu na infatigável busca de documentaçāo capaz de respaldar suas afirmativas, tal como procedia o grande renovador dos estudos da história do Brasil (8). O certo é que o motor da reação observada na III Semana Cultural de Canudos originava-se, basicamente, de uma perplexidade que, de tempos em tempos, vem acompanhando os que trabalham com Canudos, mormente na Bahia(9). Tem sido observado, através dos registros dos visitantes do Núcleo Sertão e do Centro de Estudos Euclides da Cunha - Uneb, um contraste gritante entre a quantidade de pesquisadores que vem freqüentando as duas instituiçōes e as relativamente numerosas publicaçōes dedicadas ao estudo daquele que pode ser considerado o mais denso, complexo e importante fato histórico brasileiro. Hoje, os pesquisadores brasileiros de Canudos estão em nítida minoria em face dos procedentes de outros países, até mesmodo Japão! Paralelamente-e, aoque parece, em sintonia com a reduzida freqüência sentida - não tem sido assinalada uma freqüência maior de obras que objetivem os aspectos mais obscuros da temática canudense, nem a elevaçāo qualitativa do seu teor pode ser registrada (10). Ao que tudo indica, parte considerável do que tem sido produzido não tem ido além da repetiçäo dos mesmos chavōes, de descriçōes lineares do episódio ou dos velhos e gastos apelos emocionais aos absurdos atentados contra os direitos humanos cometidos pela repressão republicana.

De raro em raro, surge uma abordagem original ou estudos que se apresentam com um mínimo de respeito às fontes e rigor científico. A grossa maioria peca por um excesso de "criatividade" tendente a borrar por completo a fronteira, que sempre deve existir, entre a obra de ficção e a histórica, tão bem estabelecida por José Honório Rodrigues: "O historiador não cria, como na ficção, antes recria um mundo realmente vivido, sofrido ou aproveitado" (11).

$\mathrm{Na}$ realidade, a vertente ficcionista da história de Canudos não se inicia, como comumente se pensa, com o livro de Edmundo Moniz, A Guerra Social de Ca- 


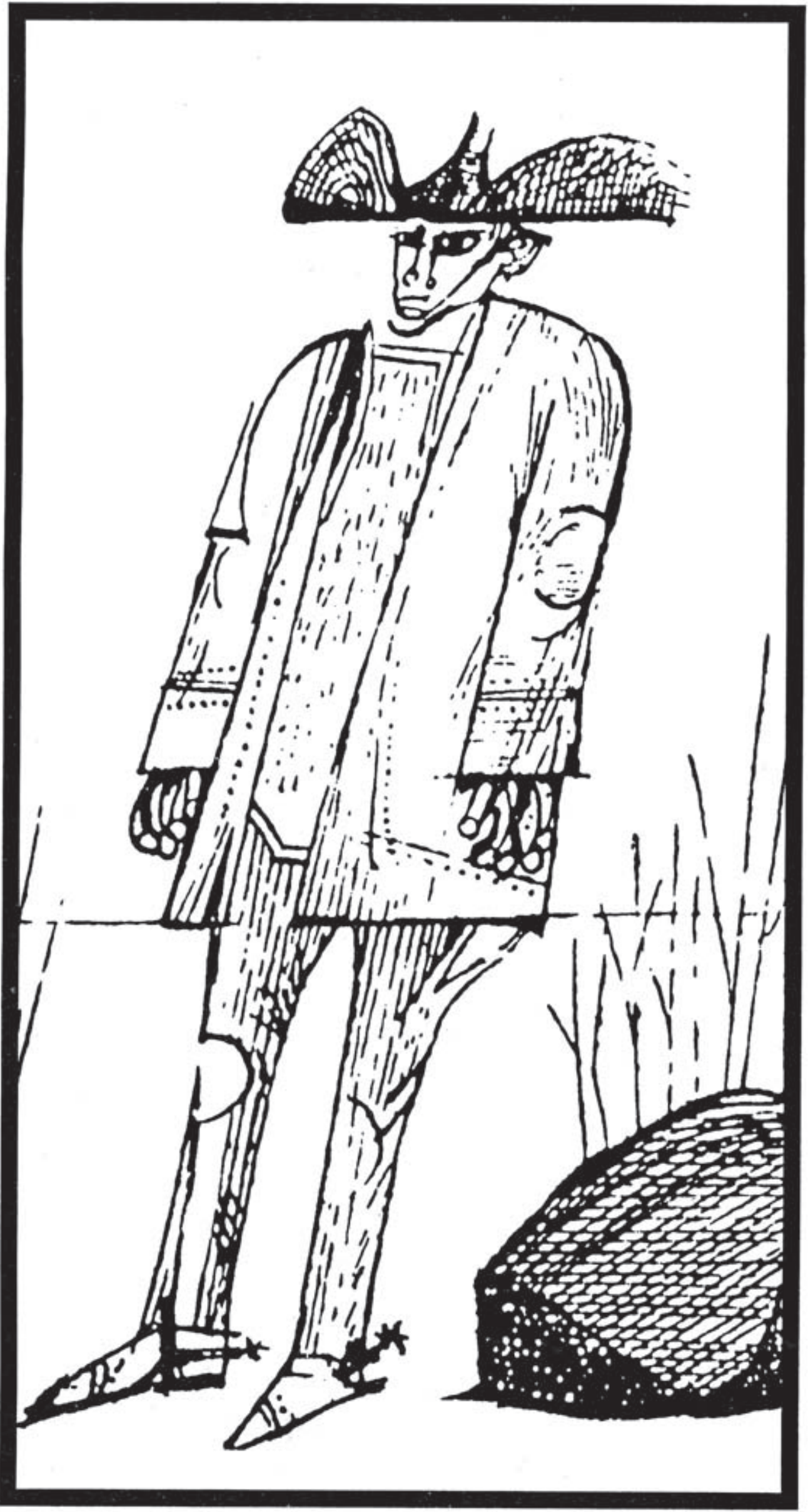

7 Uma rápida consulta a biblio. grafia canudense, a partir da decada de 60 , permitira veri. ficar a veracidade do que é afirmado.

8 Analogamente, assim como Capistrano liberta a nossa história das poias da historiografa officlal varnha geniana. por melo da critica competente e lúcida que faz do saber historico da sua época, o protessor Calasans 6 o responsável pela liberta. çáo dos estudos canudenses. entáo aprisionados na "gaiola de curo" de Os Sertóes.

9 Possiveimente pela proximidade fisica com oe dols malores repositorios de docu. mentaçáo: o Núdieo Sertáo do Centro de Estudos Baianos da Univergidade Baianos da Universidade Federal da Bahia oo Contro de Estudos Euclides da Cu. nha da Universidade do Estado da Bahia.

10 Uma das poucas excepbes b - livro do padre Alexandre Oten SVD sobre a religiosidade do Consolheiro. dade do Consolhoiro, intitulado S6 Dous É Grande. Entretanto, o mais comum tem sido o surgimento de tex. tos que denotam uma indesculpável leviandade, seja em questdes de some. nos, como a data do nasci. mento do Conselheiro - a certidiso de batismo do beato está publicada há quase 25 anos! -seja em outras mais graves o até risiveis como oxisteincla mencionada por uxistincla, mencionada por um autor, do um saveiro de bandeira estrangoira (sic) que teria sido apreendido, no porto de Salvador, por ordern do cel. Moreira César. O autor prefore náo tecer comentari. es sobre a producho thistorlca" editada pela diocese de Paulo Aloneo, à qual perten c Canudos, e pelo Movimen to dos Trabahadores Rurais Sem Terra, devido as suas fi. nalidades exclusivamente panfotárias. - História, p. 79. 
nudos. O que origina toda uma versão romanceada da tragédia desencadeada nos sertōes da Bahia entre 1896-97é, como nāo poderia deixar de ser, uma obra literária muitopouco conhecida. Publicada em 1903 (meiadúzia de anosapósaguerra...), intitulase $O$ Ideólogo. Seu autor, Fábio Luz, leu a obra de Kropotkine, Memórias de um Revolucionário, que muito o impressionou. Daí que, interpretando à sua maneira as idéias do líder russo, Fábio Luz decidiu aplića-las a Canudos, ainda efervescente e enigmático na cabeça da intelectualidade brasileira que, diga-se de passagem, nada fez contra o feroz extermínio, quando não o apoiou. $\mathrm{O}$ trecho do livro de Luz que nos importa é o seguinte:

"-Pois é o que lhe digo, meu caro. Uma horda inteira de bandidos. Não se sujeitavam às leis, e viviam lá a seu modo. Fez bem o governo, fez um Estado no Estado!

- Foi uma crueldade sem nome, Sr. Comendador, disse Anselmo. Que mal fazia aquele núcleo independente? Eles eram pacíficos. Faziam propaganda religiosa e edificavam igrejas. Queriam a paz dos humildes e viviam em uma comunidade invejável. $O$ governo republicano foi tão cruel para aquela pobre gente, como seria o Czar da Rússia. Lembra-se dos Dukhobors? Tolstói era fidalgo, era nobre, fez-se campônio. Antônio Conselheiro fez-se orientador das massas, tirou do catolicismo uma nova religiâo, aplicou o doce comunismo cristão aos sertanejos jagunçose tais eram seus dotes morais e o seu prestígio intelectual que formou uma comuna exemplar nos sertōes inóspitos. E, lá na santa paz de uma religião social por ele inventada para uso dos humildes, fundou Canudos-umacidade de palha, onde a fraternidade $e$ a igualdade foram encontrar a verdade de sua significação. Tolstói é um homem culto, um homem de letras, um apóstolo: Antônio Conselheiro era um homem do povo, quase analfabeto. Entretanto foi igual sua missão na terra. Tolstói continua a sua propaganda mística com a sua religiāo pura dos Evangelhos. Antônio Conselheiro evangelizou sua religião nova, e organizou a seu modo a sua comuna sem governo e sem potentados. Eles eram felizes nos inóspitos sertōes, felizes na sua humildade e na sua fé. Para se defende- rem das hostilidades da sociedade perversa que os cercava eles sabiam manobrar as armas. Eram supersticiosos e tinham uma religião nova, diziam. Que tinha a República com a religiāo deles nova ou velha? Mas era a organização livre que era preciso destruir. Era no exemplo; era no modelo de organização comunal; era na liberdade sem peias; era na felicidade sem as complicações solícitas dos governos que estava o perigo. Eles eram felizes na sua fé ingênua, na sua igualdade de irmãos. O Estadonãopodia consentir em tal.Era uma revolução na organização social; era a retrogradação!!! Um covil de vagabundos, que nâo traziam ao comércio o produto de sua lavoura ou de sua indústria, um centro de rebeldia, onde havia até igualdade no modo de vestir, onde não se gastavam sedas, e as jóias como todos os objetos de luxo não tinham cotação, deviam desaparecer. Que sociedade atrasada! Não havia exploração! todos iguais! Era urgente o extermínio a ferro e a fogo! E eles mostraram como os humildes, para defender sua felicidade, e a paz do seu lar, sabem lutar. As expediçōes partiram e as expedições foram derrotadas. Honra aos jagunços! -Ora, meu amigo, é até ridículo comparar Antônio Conselheiro a Tolstói.

-Ridículo por quê? Se na Europa tivesse aparecido o Conselheiro, se tivesse como Tolstói ou Kropotkine feito sua propaganda pelos campos, se tivesse escrito livros em que pusesse em evidência suas teorias humanitárias, o senhor olharia compungido o seu retrato, teria veneração pelas longas e brancas barbas do asceta, e lhe daria um lugar distinto na sua galeria de benfeitores da humanidade. Ele era um simples sertanista, tinha sentido com os retirantes do Ceará o flagelo da seca e da fome, e talvez nos areais intérminos onde a luz abrasadora do Sol calcina os cadáveres daqueles que abandonaram terras, culturas, laresem busca de uma gota d'água, tivesse, impotente, visto uma geração inteira extinguir-se ao sopro cálido do flagelo. Contra ele talvez se tivessem conspirado terras e céus; e ele ficou só e resignado, e não tendo família, pois a esposa lhe roubaram, viveu para a Humanidade.

Porventura os mártires do cristianismo que osenhorvenera por esnobismoeram 


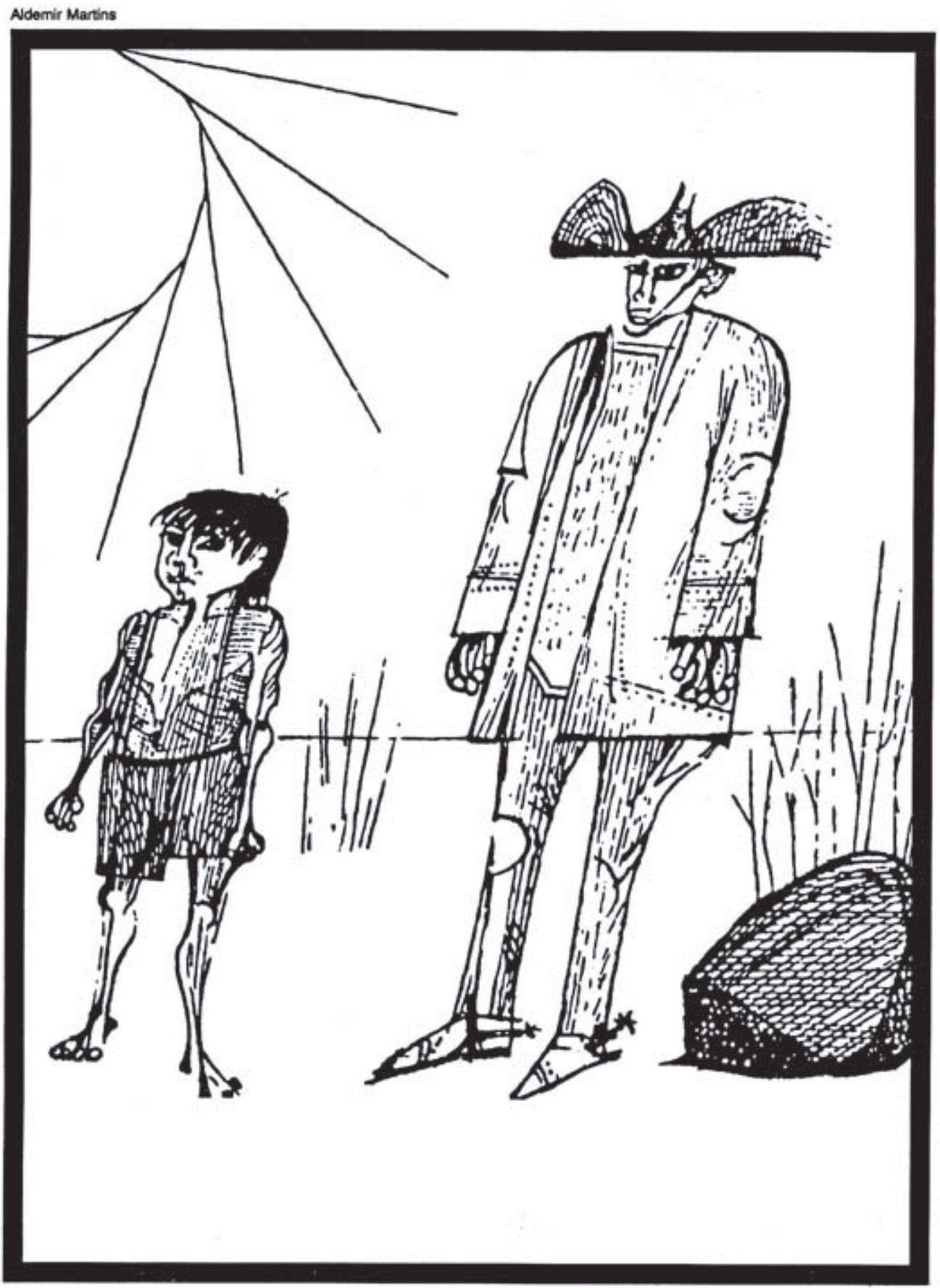

diferentes dele? Não eram, como ele, do povo; simples, humildes e ignorantes? Ele tinha entretanto a intuição da igualdade, e foi muito além do seu tempo. Um dia Antônio Conselheiro há de ser admiradocomooprecursor de umaidéia nova de largos horizontes" (12).

Com efeito, se não temos motivos suficientes para louvar as virtudes literárias do autor de OIdeólogo, não há como negar-lhe uma invejávelcapacidade profética.Luztem aconfirmá-lomodernamente uma talpletora de "história" e de "historiadores" que chega a colocar em risco de extinção não somente o conhecimento da epopéia conselheirista, fato crucial para o entendimento da história pátria, como o próprio ofício de historiador. Parece que, a prosseguirmos no rumo atual, brevemente chegaremos a uma outra verdade, expressa, momentos antes de sua morte, pelo coronel Tamarindo, subcomandante da expedição Moreira César e cujo registronãoescapou a Euclides da Cunha:

"É tempo de murici cada qual cuide de si..."
12 Wison Martins, História da in. toligdncia Brasileira, V. PP. 224.5 . 